\title{
BM] Global Health Going beyond killer apps: building a better mHealth evidence base
}

To cite: Peiris D, Miranda JJ, Mohr DC. Going beyond killer apps: building a better mHealth evidence base. BMJ Glob Health 2018;3:e000676. doi:10.1136/ bmjgh-2017-000676

Handling editor Soumitra Bhuyan

Received 8 December 2017 Revised 8 February 2018 Accepted 9 February 2018

\section{Check for updates}

${ }^{1}$ Office of the Chief Scientist, The George Institute for Global Health, UNSW Sydney, Camperdown, New South Wales, Australia

${ }^{2}$ CRONICAS Center of Excellence in Chronic Diseases, Universidad Peruana Cayetano Heredia, Lima, Peru

${ }^{3}$ School of Medicine, Universidad Peruana Cayetano Heredia, Lima, Peru

${ }^{4}$ Center for Behavioral Intervention Technologies, Northwestern University, Chicago, Illinois, USA

Correspondence to Professor David Peiris; dpeiris@georgeinstitute.org
mHealth relates to the provision of health-related services via a mobile device. It comprises multidimensional elements including provider, patient and administrative applications. Applications include consumer education and behaviour change, wearable sensors and point-of-care diagnostics, disease and population registries, electronic health records, decision support, provider tools (communication, workflow management, professional education) and healthcare management (human resources, financial monitoring, supply chain logistics). ${ }^{1}$

Although mHealth has potential to strengthen health systems worldwide, the evidence base is immature, and consequently, the opportunities to advance knowledge remain limited. ${ }^{2}{ }^{3}$ Mobile devices and apps have become essential tools for disruptive change in many industries, but thus far, this has not happened in healthcare. Here, we discuss five interrelated reasons as to why mHealth has underdelivered and highlight challenges and opportunities for mHealth researchers.

\section{THE MYTH OF THE 'KILLER APP'}

Disruptors often rely on a 'killer app'-a highly popular application that users will consider indispensable for their needs. At last count, there were nearly 260000 health apps on the market, ${ }^{4}$ but most downloads are never opened and consistent use is extremely rare. Further, these apps are often disease siloed, focus mainly on behaviour change, gloss over privacy issues and are not integrated into any overarching healthcare structure. Such apps struggle to achieve large-scale adoption because of their failure to address the needs of diverse stakeholders. ${ }^{5}$ Most apps are consumer facing, whereas healthcare systems tend to be provider facing. This important distinction may explain why the 'killer app' approach is not the correct mindset. The diversity of users and the inability to address their varied problems results in user fickleness and ready abandonment of new technologies.
When tools are not connected to systems and human support, they are unlikely to be effective. Consequently, moving beyond a single solution focus towards a 'health ecosystem' approach is needed. ${ }^{6}$

\section{NEGLECTING USER PERSPECTIVES AND PREFERENCES}

Related to the killer app mythology is the tendency to overengineer solutions before having an opportunity to fully understand user needs, contextual factors and the size and specifics of the problem that needs addressing. The Greentree consensus outlines nine principles for digital development, emphasising frequent and in-depth user engagement in all phases of the development process. ${ }^{7}$ It stresses the importance of understanding the ecosystem, designing for scale and sustainability, addressing privacy, using open standards and taking a data-driven approach. It also emphasises the need for multidisciplinary collaborations. Although researchers are often the subject matter experts, non-health specialists such as human factors engineers, human computer interaction specialists, anthropologists and ethicists can provide strong methodological frameworks for understanding user perspectives at all stages of the development, implementation, evaluation cycle. ${ }^{8}$ By not taking a user-centred approach, we risk overengineering solutions. The most promising use of mHealth to date has not been smartphone apps, but basic functions such as short messaging service or voice calls to address specific issues such as medication adherence and promoting smoking cessation. ${ }^{910}$

\section{APPS ARE NOT PILLS}

Researchers tend to lack a good understanding of how developers operate. Two commonly used industry standards include Waterfall and Agile development. ${ }^{11}$ Waterfall is a stepwise process whereby developers iteratively revise their software at each stage of 
the product development cycle based on target audience feedback. It may be particularly appropriate for largescale system development. Agile design takes an incremental rather than sequential approach. Initial prototypes are usually simple and each development effort is completed in short sprint cycles with increasing maturity at each cycle. It is particularly useful when there is not a clear idea what might work. Whichever approach is used, initial deployments are unlikely to work perfectly. The interim goal should be a 'good enough' prototype, known in industry as the minimum viable product.

These approaches highlight differing developer and researcher perspectives. The developer's outlook is plastic, continually updating and refining a product to create novel solutions and stay ahead of the competition. By contrast, a researcher's outlook is more static where interventions are viewed as pills-specific agents that are developed and tested in isolation of other factors. These differences in perspective are often disregarded. Understanding the developer's approach can help research teams to get apps in front of users quickly, fail early and build from the lessons learnt. This approach can also avoid expensive 'scope creep' later in the development cycle when the app is more mature and user testing reveals a major redesign is needed.

\section{RIGID APPROACHES TO EVALUATE EVOLVING TECHNOLOGIES}

While we strongly support the need for evaluations with randomised controlled trials (RCTs), there are several considerations in applying this design in mHealth. First, traditional RCT designs reflect 'the static view' described above-assuming an intervention is 'fixed' and external factors are standardised or adjusted for to avoid introducing a bias. This is anathema to software development where iteration, bug fixes and new releases as user experience grows are the norm-'the perpetual beta'. The key consideration here is that we test principles rather than fixed $a p p s .{ }^{12}$ The app market is constantly evolving but principles remain relatively constant and generate generalisable knowledge of public health interest. Second, RCTs are good at testing efficacy but are not so good at answering questions related to the implementation strategy. ${ }^{13}$ Incorporation of theory-informed frameworks for understanding factors associated with adoption and non-adoption are therefore essential to evaluate programmes and generate knowledge that can be applied to other settings. ${ }^{14} \mathrm{~A}$ third and unexplored area is postmarketing surveillance mechanisms to safeguard against unintended consequences derived from mHealth-related activities. $^{15}$

\section{WHAT ARE THE PRIORITIES OF THOSE WHO PAY FOR MHEALTH TECHNOLOGIES?}

Public and commercial payers of health services play a central role in determining whether mHealth can be adopted at scale. Innovation in the business model is just as important as the apps themselves in promoting disruption. Greater attention to business model specifics may stimulate different research questions. From a researcher's perspective, the priority is to demonstrate clinical effectiveness. This contrasts with the payer's perspective which is broader and includes factors such as reduced administrative burden, improved workflows, greater patient and provider engagement and improved quality of care and outcomes at lower costs. ${ }^{16}$ The macroeconomic environment is also key to driving particular business models. While profits may be greater in high-income countries, the largest mHealth market in terms of user numbers will be in emerging economies. Just as the pharmaceutical industry tends to be segmented into low volume, high margin products for rich countries and high volume, cheaper products for poorer countries, mHealth markets are likely to evolve differently depending on the payer, provider and consumer environment. It is therefore important that the research community generate evidence on effective business models as much as effective apps.

\section{CONCLUSION}

Although some may be disillusioned by the lack of 'blockbuster' mHealth trials, we are optimistic that the evidence base for mHealth will grow substantially in coming years. Particular challenges remain, especially in low-income and middle-income country settings where literacy, health literacy, unavailability of smartphones and limited access to reliable data connectivity all pose adoption challenges. However, these factors are improving rapidly, and the opportunities for future growth are substantial. With increasing knowledge of what works and what the challenges are, we will arrive at a more nuanced understanding of the role of mHealth in improving health and healthcare.

Contributors DP led the writing of the manuscript with important intellectual and editing input from JM and DM.

Competing interests None declared.

Provenance and peer review Not commissioned; externally peer reviewed.

Data sharing statement No additional data are available.

Open Access This is an Open Access article distributed in accordance with the Creative Commons Attribution Non Commercial (CC BY-NC 4.0) license, which permits others to distribute, remix, adapt, build upon this work non-commercially, and license their derivative works on different terms, provided the original work is properly cited and the use is non-commercial. See: http://creativecommons.org/ licenses/by-nc/4.0/

(C) Article author(s) (or their employer(s) unless otherwise stated in the text of the article) 2018. All rights reserved. No commercial use is permitted unless otherwise expressly granted.

\section{REFERENCES}

1. Labrique $A B$, Vasudevan $L$, Kochi $E$, et al. mHealth innovations as health system strengthening tools: 12 common applications and a visual framework. Glob Health Sci Pract 2013;1:160-71.

2. Peiris D, Praveen D, Johnson $C$, et al. Use of mHealth systems and tools for non-communicable diseases in low- and middleincome countries: a systematic review. J Cardiovasc Trans/ Res 2014;7:677-91. 
3. Sondaal SF, Browne JL, Amoakoh-Coleman M, et al. Assessing the effect of mHealth interventions in improving maternal and neonatal care in low- and middle-income countries: a systematic review. PLoS One 2016;11:e0154664.

4. The mHealth app market is getting crowded reaching the 259.000 apps. 2016 https://www.ticbiomed.org/2016/10/13/the-mhealthapp-market-is-getting-crowded-reaching-the-259-000-apps/ (accessed 08 Dec 2017).

5. Mohr DC, Weingardt KR, Reddy M, et al. Three problems with current digital mental health research and three things we can do about them. Psychiatr Serv 2017;68:427-9.

6. Mechael P. Barriers and gaps affecting MHealth in low and middle income countries: policy white paper. $2010 \mathrm{http}: / / \mathrm{www}$. globalproblems-globalsolutions-files.org/pdfs/mHealth_Barriers White_Paper.pdf (accessed 8 Dec 2017).

7. Principles for Design \& Development. http://digitalprinciples.org/ (accessed 8 Dec 2017).

8. Ben-Zeev D, Schueller SM, Begale M, et al. Strategies for mHealth research: lessons from 3 mobile intervention studies. Adm Policy Ment Health 2015;42:157-67.

9. Rubinstein A, Miranda JJ, Beratarrechea A, et al. Effectiveness of an mHealth intervention to improve the cardiometabolic profile of people with prehypertension in low-resource urban settings in Latin America: a randomised controlled trial. Lancet Diabetes Endocrinol 2016;4:52-63.
10. Scott-Sheldon LA, Lantini R, Jennings EG, et al. Text messagingbased interventions for smoking cessation: a systematic review and meta-analysis. JMIR Mhealth Uhealth 2016;4:e49.

11. 10 differences between agile and waterfall methodology. 2016 https://blog.flatworldsolutions.com/10-differences-agile-waterfallmethodology/ (accessed 8 Dec 2017).

12. Mohr DC, Schueller SM, Riley WT, et al. Trials of intervention principles: evaluation methods for evolving behavioral intervention technologies. J Med Internet Res 2015;17:e166.

13. Geng EH, Peiris D, Kruk ME. Implementation science: relevance in the real world without sacrificing rigor. PLoS Med 2017; 14:e1002288

14. Greenhalgh T, Wherton J, Papoutsi C, et al. Beyond adoption: a new framework for theorizing and evaluating nonadoption, abandonment, and challenges to the scale-up, spread, and sustainability of health and care technologies. J Med Internet Res 2017; 19:e367.

15. Mohr DC, Cheung K, Schueller SM, et al. Continuous evaluation of evolving behavioral intervention technologies. Am J Prev Med 2013;45:517-23.

16. PwC. Emerging mHealth: paths for growth: PwC. https://www.pwc. $\mathrm{com} / \mathrm{g} x /$ en/healthcare/mhealth/assets/pwc-emerging-mhealth-full. pdf (accessed 8 Dec 2017). 